\title{
Estudo piloto sobre o discurso de pesquisas científicas em Design da informação: uma abordagem crítico-semântica da coerência da estrutura textual
}

\author{
A pilot study regarding the discourse of scientific \\ research in Information Design: a critical-semantic \\ approach of the coherence of textual structure
}

Elizabelle Pereira Costa, Meiriédna Queiroz Mota, Solange Galvão Coutinho, Eva Rolim Miranda

análise semântica, metodologia científica, discurso científico

\begin{abstract}
Este artigo apresenta o resultado de uma pesquisa piloto que investiga, de forma crítica, a estrutura semântica do discurso de textos científicos que foram publicados em congressos e periódico da área do Design da Informação. O procedimento envolveu a análise de dez artigos em língua portuguesa, cujos temas são relacionados ao Design da Informação e cujas metodologias abordam procedimentos científicos não projetuais. O objetivo principal foi expor os pontos positivos e as fragilidades das relações entre o discurso dos objetivos planejados, das metodologias utilizadas e das conclusões extraídas pelos pesquisadores ao final de suas experiências. Para tal fim, foram utilizados dois instrumentos de análise distintos: a escala de diferencial semântico, desenvolvida em 1957, e o software de análise semântica Tropes versão 8.4 de 2013. O emprego dessas ferramentas mostrou que há fragilidade na transmissão de ideias e na coerência entre as estruturas da maioria dos textos observados, apontado a necessidade de atenção na estipulação de objetivos claros e na escolha de metodologias adequadas aos objetivos para, assim, promover conclusões coerentes.
\end{abstract}

semantic analysis, scientific methodology,

This paper presents the results of a pilot study, together with a critical investigation of the semantic structure of the discourse in scientific papers, which have been published at conferences and in journals in the area of information design. The procedure involved the analysis of ten articles in Portuguese, with themes related to information design involving methodologies for non-projective scientific procedures. The main objective was to expose the strengths and weaknesses of the relationship between the discourse of the planned objectives, the methodologies used and the conclusions drawn by the researchers at the end of their experiments. To this end, two distinct analytical tools were employed: the semantic differential scale, developed in 1957, and the semantic analysis software - Tropes 8.4 (2013). These tools have demonstrated that there is weakness in both the transmission of ideas and structural coherence amongst the majority of the observed texts, indicating the need for special attention when specifying clear objectives and in selecting the most appropriate methodologies for the desired objectives, thus promoting consistent conclusions. 


\section{Introdução}

Pesquisas e estudos científicos são submetidos a padrões de organização estrutural que promovem certo grau de unicidade entre eles. Seja de natureza nacional ou internacional, instituições científicas criam normas que regem a produção textual e buscam facilitar o processo de comunicação entre estudiosos das diversas áreas do conhecimento.

Tais regras, entretanto, não devem ser associadas, tão somente, ao escopo da organização visual. Além da perspectiva visual, os textos científicos possuem características linguísticas próprias visando clareza e, consequentemente, entendimento da informação disponibilizada.

O processo de comunicação verbal textual implica habilidades especificas de escrita - por parte do remetente da mensagem - para transmitir, de maneira mais fiel possível, suas intenções ao destinatário. Para tanto, o cuidado com escolha de palavras, expressões e significados da oratória é primordial. Esta exposição metódica de ideias sobre determinado assunto é o que constrói o discurso.

Para Foucault (1996), o discurso é uma estrutura também social partilhada entre autor e receptor no processo de comunicação. Ou seja, o ato comunicativo se concretiza através da interação de experiências do produtor do discurso e das experiências do sujeito que recebe e decodifica a mensagem.

Este movimento de codificação e decodificação constitui o ato de comunicar e está envolto em uma teia de conceitos e significados próprios dos estudos da Semântica.

Para fins deste estudo, faz-se uso da semântica do discurso como mecanismo para entender as intenções do locutor por meio de análise da significação, construção do raciocínio lógico e discurso cientifico.

Em um estudo preliminar, analisando dez artigos científicos publicados em congressos, simpósios e revista nacionais conceituados dentre os estudiosos da área do Design, buscou-se compreender os níveis de eficiência do discurso científico no universo do Design da Informação no que se refere à exposição de pesquisas ao mundo acadêmico. O objetivo foi apontar as características positivas e as fragilidades presentes na relação entre os objetivos estipulados nas pesquisas, as metodologias utilizadas e as conclusões finais de cada estudo. Como esta investigação se encontra em processo de construção, ainda não é possível inferir resultados globais conclusivos, diante da pequena amostra, entretanto podemos identificar ocorrências similares provenientes do discurso.

Mesmo com uma amostra reduzida, como princípio básico, optamos por certa variedade de veículos de divulgação científica, de forma a conhecer a possível multiplicidade ou similaridade de discursos do campo, ou seja, aqueles referentes a congressos/ 
simpósios de Design, Design da Informação e correlatos; e do único periódico especializado em Design da Informação do país.

Os procedimentos seguidos para a escolha das amostras foram os seguintes:

1. Artigo publicado nos últimos dez anos, cujo tema de discurso estivesse relacionado ao campo de exploração do Design da Informação como, por exemplo, interface impressa ou digital, educação e linguagem gráfica;

2. Pesquisa em anais de congressos/simpósios e periódicos nacionais com bom conceito na avaliação Qualis da Coordenação de Aperfeiçoamento de Pessoal de Nível Superior (Capes) e cujo tema principal seja relacionado ao Design;

3. Pesquisa em anais de congressos/simpósios e periódicos nacionais com bom conceito na avaliação Qualis da Coordenação de Aperfeiçoamento de Pessoal de Nível Superior (Capes) e que também admitam a publicação de artigos relacionados ao Design;

4. Escolha de amostras publicadas em seções relacionadas ao Design da informação (critério escolhido pelas próprias publicações especializadas);

5. Escolha do único periódico nacional em Design da Informação, a Infodesign, Revista Brasileira de Design da Informação.

Justifica-se também a escolha de uma amostra reduzida, na perspectiva de proceder a um estudo preliminar eminentemente qualitativo, de forma a obter uma visão minudenciada dos dados.

Em primeiro lugar, as pesquisadoras, do presente estudo, analisaram diversos artigos e selecionaram as dez amostras para a aplicação dos dois instrumentos de naturezas distintas. Em seguida, com auxílio da ferramenta Escala de Diferencial Semântico (EDS), desenvolvida em 1957, foi feita a leitura das amostras e de acordo com as explicações oferecidas nos próprios textos, foram identificados os elementos-chave a serem analisados nos: objetivos, metodologia e conclusões.

No segundo momento, as mesmas dez amostras foram submetidas à investigação automática do software Tropes v 8.4 que analisa a semântica de textos e cuja versão final remonta do ano de 2013. Os dados, convertidos em gráficos, construíram cenários de relações contextuais passíveis de comparações com os dados obtidos pela ferramenta EDS.

Por meio destas duas ferramentas foi traçado uma zona de união entre dois períodos distintos do universo de análise semântica do discurso que buscou diminuir as limitações impostas pelas características de cada ferramenta.

Por fim, os resultados das duas observações das amostras construíram bases que possibilitou avaliar a produção do discurso científico como um processo que requer a capacidade de associar os componentes da pesquisa de modo a "conversarem" entre si e promoverem coesão discursiva e metodológica. 


\section{Semântica do discurso}

Elaborar um texto bem estruturado requer atenção aos padrões de linguagem que envolve os indivíduos que fazem parte do processo de comunicação. Em outras palavras, fazer-se entender através de um texto exige do autor a capacidade de escolher palavras e expressões que sejam suficientemente claras para os leitores. Esta clareza, entretanto, não diz respeito apenas ao rebuscamento da língua, mas também à obediência às três dimensões do discurso linguístico:

1. A sintaxe: Preocupa-se com a organização dos elementos da oração, por exemplo, da palavra em uma frase ou das frases em um discurso, dando sentido à mensagem.

2. A semântica: Área voltada ao estudo do significado e interpretação do significado das estruturas do discurso.

3. A pragmática: Analisa o discurso através da relação que seus elementos têm com os sujeitos envolvidos no processo comunicativo.

Atender a estas três dimensões é o objetivo de textos que pretendam transmitir informação de maneira eficiente. O processo é complexo e requer habilidade para equilibrar tais características num único impulso comunicativo.

Scherer (2009) utiliza o pensamento de Kintsch (1998) para explicar as interferências presentes no processo comunicativo textual.

Sempre que uma mensagem é emitida através de um texto, estruturas variadas entram em cena, de modo mais ou menos explícito. Em geral, na comunicação interpessoal comum, parte da mensagem é dada explicitamente em uma base textual, outra parte precisa ser construída ou inferida pelo leitor através do apoio de traços textuais que auxiliam o processamento de forma coesiva e coerente, e outra parte necessária para a compreensão leitora é oriunda de informação extratextual, a qual reside no conhecimento de mundo do leitor (Kintsch, 1998: 78).

Os textos científicos, por sua parte, devem estar em adequação às convenções de formatação textual atribuída por instituições regulamentadoras e de acuidade linguística para expor argumentos passiveis de defesa ou de contestação por parte do público acadêmico.

Por sua própria natureza argumentativa, o discurso científico é construído com a finalidade de ser compreendido, contestado e testado. Para tanto, é preciso ser coerente em sua defesa de ideias. Expor tais ideias, entretanto, exige do autor a capacidade de atribuir significados claros aos termos e expressões que utiliza, de modo a não haver ambiguidade na interpretação.

Salomon (1999:245) faz uma compilação de requisitos básicos que norteiam a produção de textos de base científica:

- Exatidão;

- Clareza;

- Simplicidade;

- Correção gramatical; 
- $\quad$ Linguagem objetiva e estilo direto;

- Equilíbrio na disposição e tamanho das partes;

- Emprego da linguagem técnica necessária, evitando-se o preciosismo e a pretensão;

- Apresentação dos recursos técnicos da redação para que a apresentação atinja melhor seu fim.

Esta lista pode ser ampliada pelos pressupostos de Barrass (1979:31-33) com a adição de três itens que, segundo ele, se aproximam mais das necessidades do leitor:

- Imparcialidade: expor os pressupostos que dão base a sua argumentação;

- Ordem: coerência na ordem de expor a informação;

- Acuidade: cuidado no tratamento dos dados e na elaboração das inferências que deles extrai. Dar condições para a reprodução do experimento e para a verificação das conclusões.

Aliar todos os pontos destacados nestas duas listas de requisitos é uma tarefa difícil, mas importante para o universo acadêmico. Este processo transmite a preocupação da comunidade científica em imprimir unicidade as suas produções e manter distinção no nível de abordagem do discurso argumentativo. Em suma, é uma forma de manter um estilo de comportamento discursivo.

Para justificar a utilização da análise semântica do discurso nesta pesquisa, toma-se como base o conselho dado por Rudio (1978:23), quando diz que "Procura-se, na ciência, fazer a comunicação na base dos significados e dos referentes e não apenas na própria palavra”. Portanto, a postura e abordagem do discurso linguístico são tão importantes quanto o hermetismo do funcionamento sintático.

\section{Metodologia de análise}

Analisar o discurso de um texto científico é demasiado laborioso e requer o entendimento de que o mais importante é a coerência argumentativa. Esta coerência é alcançada quando os componentes da pesquisa (título, resumo, objetivos, metodologia, experimento, conclusões, referências) - que também são elementos textuais - estão interligados num sistema cíclico no qual existem discursos com zonas comuns de foco.

Para investigar os componentes mais representativos do discurso do texto cientifico, este trabalho elegeu três estruturas básicas: Objetivos (que devem nortear toda pesquisa e toda conduta do pesquisador/ autor), Metodologia (que é responsável por eleger os meios de atingir as metas estipuladas nos objetivos) e Conclusões (que são o resultado final de toda a experiência cientifica e traz consigo as inevitáveis marcas do sucesso ou insucesso da relação entre objetivos e metodologia).

$\mathrm{O}$ intuito foi estabelecer um sistema síntese que possua as características fundamentais do discurso científico e que, ainda assim, 
seja capaz de representar a totalidade dos discursos apresentados nos dez artigos analisados (Figura 1).

Figura 1 Representação de um sistema síntese cíclico de inter-relação entre os componentes fundamentais da pesquisa científica.

(Elaborada pelos autores)

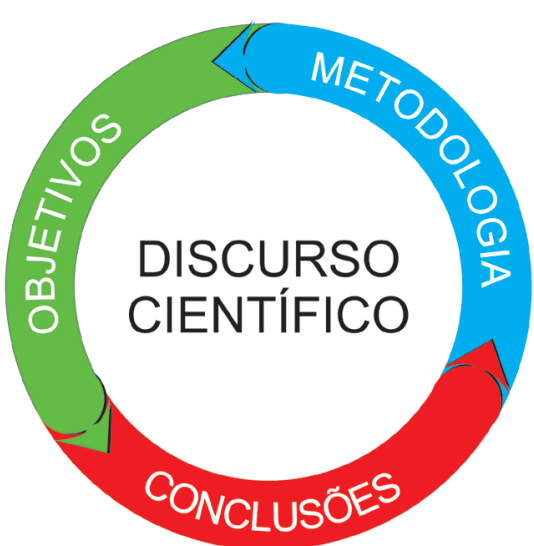

Cada um destes componentes tiveram seus discursos analisados separadamente e, posteriormente, suas caracteristicas foram comparadas entre si.

Para desenvolver uma investigação abrangente e de base sólida, foram escolhidas duas ferramentas de análise de semântica de natureza distintas. No primeiro momento, a análise se concentrou na aplicação da Escala de Diferencial Semântico (EDS) que é um instrumento de análise corrente e elaborado a partir da abordagem dos estudos de psicologia na segunda metade do século XX.

O objetivo de aplicar tal ferramenta se justifica na necessidade de um mecanismo de investigação de carater subjetivo, de modo a se adaptar às nuances de interpretação exigidas por uma análise semântica.

O segundo momento da análise foi destinado a submissão dos componentes do discurso dos artigos a uma ferramenta mais atual. Para tanto, foi escolhido o software Tropes v 8.4, cujas funções coordenadas por parametros computacionais são capazes de identificar o foco no discurso de textos e expõe dados bastante precisos sobre relações contextuais entre palavras e entre conceitos.

Utilizar um software representa aceitar a evolução das ferramentas e das formas de enxergar um problema a ser pesquisado. Embora a capacidade de interpretação de um software seja limitada, a possibilidade de extrair dados quantitativos precisos é um advento que não pode ser rejeitado.

Após a aplicação dos dois instrumentos de análise e da interpretação dos dados obtidos com cada um deles, foram explorados os resultados gerais que caracterizaram os discursos dos artigos analisados e foram construídas ponderações sobre as técnicas da EDS e do Tropes v 8.4. 
Para além dos critérios já apontados na introdução deste artigo, a escolha dos mesmos seguiu três outros parâmetros:

- Todos os artigos deveriam ser escritos em lingua portuguesa para facilitar a interpretação dos significados dos termos e conceitos expostos nos discursos;

- Todos os artigos deveriam pertencer à área do Design da Informação para promover um estudo desta área específica;

- Todos os artigos deveriam apresentar pesquisas cujas metodologias são de natureza não projetual para promover homogeneidade no espaço amostral analisado.

A busca por artigos científicos que se encaixassem em tais parâmetros resultou na eleição de dez estudos assim divididos:

- Três artigos publicados no 9ํㅡㅁ Congresso Brasileiro de Pesquisa e Desenvolvimento em Design (2010);

- Três artigos publicados na Infodesign: revista brasileira de design da informação $(2013,2014)$;

- Um artigo publicado no XII Simpósio Brasileiro de Jogos e Entretenimento Digital (2013);

- Um artigo publicado no XIII Congresso de Ciências da Comunicação (2012);

- Um artigo publicado no II Simpósio Hipertexto e Tecnologias na Educação (2008);

- Um artigo publicado no $6^{\circ}$ Congresso Internacional de Design da Informação (2013).

Por se tratar de um estudo preliminar, o pequeno número de amostras representa um esforço inicial para reconhecimento e ajuste da metodologia de avaliação.

\section{Escala de Diferencial Semântico - EDS}

Desenvolvida por Charles Osgood, George Suci e Percy Tannenbaum em 1957, a escala de valoração do diferencial semântico é uma ferramenta de avaliação cujos fundamentos se baseiam na psicologia e buscam estudar a estrutura do sentido de objetos, situações e conceitos.

A análise é processada por meio de uma tabela (ver tabela 1) responsável por dividir um conceito (conceito de referência) em dois polos com significação oposta (polo positivo e polo negativo). Entre os polos é estabelecida uma grade de níveis de valoração que ajudam a aproximar a tendência de associação a um determinado conceito. 
Costa E. P., Mota M. Q., Coutinho S. G. \& Miranda E. R. | Estudo piloto sobre o discurso de pesquisas científicas em Design da informação: uma abordagem crítico-semântica da coerência da estrutura textual

Tabela 1 Estrutura do quadro diferencial semântico em escala de valoração.

\begin{tabular}{lllllllll}
\hline CONCEITO DE REFERENCIA & POLO NEGATIVO & & NIVEIS DE VALORAÇÃO & & POLO POSITIVO \\
\hline & & -3 & -2 & -1 & 0 & +1 & +2 & +3 \\
\hline CONCEITO 1 & Conceito 1 negativo & & & & & Conceito 1 positivo \\
\hline CONCEITO 2 & Conceito 2 negativo & & & & Conceito 2 positivo \\
\hline CONCEITO 3 & Conceito 3 negativo & & & & & Conceito 3 positivo
\end{tabular}

A primeira ação para a utilização desta ferramenta é, portanto, estabelecer os conceitos que se pretende analisar de acordo com o objetivo traçado.

No caso do presente estudo, foram determinados cinco conceitos que aglutinam as principais características listadas por Salomon (1999) e Barrass (1979) em suas buscas pela estruturação do discurso científico e cada qual foi, por sua vez, dividido em dois polos de valoração:

- Clareza: a mensagem é relevante e não apresenta redundância. Polos de valoração: Claro / Confuso;

- $\quad$ Objetividade: a mensagem é considerada simples (evitando significados dúbios e a utilização de termos excessivamente rebuscados). Polos de valoração: Objetivo / Evasivo;

- Concisão: a mensagem tem a capacidade de expressar muitos conceitos em poucas palavras. Polos de valoração: Conciso / Prolixo;

- Coerência: a mensagem possui ideias, fatos e opiniões expostos de forma organizada e ordenada. Polos de valoração: Coerente / Incoerente;

- $\quad$ Acuidade: a mensagem apresenta cuidado na exposição de observações, precisão na mensuração de dados e atenção no registro das observações sem aferições que extrapolem a real dimensão dos dados obtidos. Polos de valoração: Perspicaz / Inépcio.

A tabela 2 mostra a aplicação destes conceitos e de seus polos de valoração ao quadro de diferencial semântico. Desta forma, ajuda a entender como as ideias podem transitar entre polos distintos sem que, necessariamente, abranjam apenas um significado fechado.

Tabela 2 Quadro diferencial semântico aplicado aos conceitos analisados nesta pesquisa 


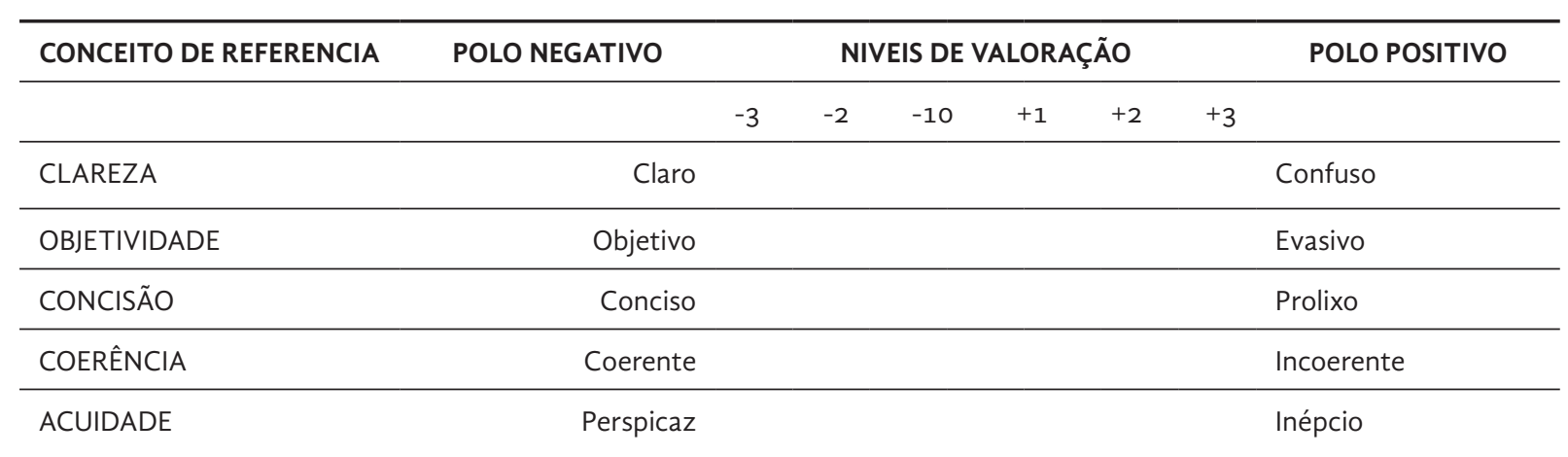

\subsection{Resultados da análise com o EDS}

Após a construção do quadro, já munido dos conceitos a serem explorados (Clareza, Objetividade, Concisão, Coerência e Acuidade), as pesquisadoras isolaram as estruturas textuais (objetivos, metodologias e conclusões) de cada uma das dez amostras de artigos científicos.

A avaliação foi realizada pelas próprias pesquisadoras que eram professoras e estudantes do curso de doutorado em Design da Universidade Federal de Pernambuco - UFPE. Cada avaliadora investigou as dez amostras classificando seus objetivos, metodologias e conclusões de acordo com as especificações estabelecidas na organização da Escala de Diferencial Semântico planejada para o presente estudo.

Os resultados de tal análise estão expostos nos gráficos a seguir.

Gráficos 1a e 1b Analise dos objetivos das amostras quanto à clareza e à objetividade
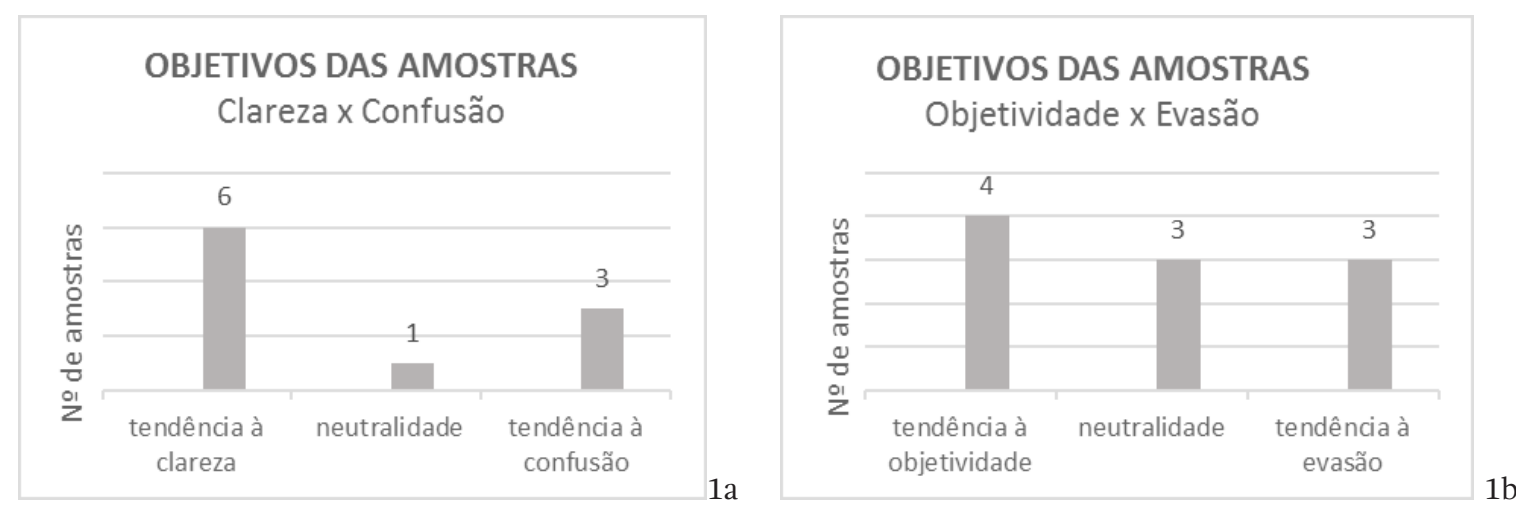

Os gráficos 1a e $1 \mathrm{~b}$ mostram que a maioria dos artigos analisados (n6/n10) possuem objetivos com discursos que foram considerados claros, porém, é importante destacar que este número representa apenas $60 \%$ do total das amostras, o que indica certo equilíbrio entre a positividade na clareza e a fragilidade no conflito dos autores das amostras em expressar suas metas. Também é possível verificar que 
há interferências na capacidade dos autores das amostras serem objetivos quando observado que, apenas quatro em dez amostras foram consideradas objetivas na exposição de suas metas.

A clareza e a objetividade dos discursos dos objetivos estão intimamente entrelaçadas, pois facilitam que as metas sejam entendidas pelo leitor desde o primeiro contato e que permaneçam em sua mente até o termino da leitura.

A análise das amostras expôs que a característica 'concisão' esteve atrelada à clareza do discurso dos objetivos. Os textos com tendência à concisão apresentaram as ideias com maior clareza e, em caminho paralelos, com maior coerência.

Gráfico $\mathbf{2 a} \mathbf{e} \mathbf{2 b}$ Analise das metodologias das amostras quanto à clareza e à objetividade
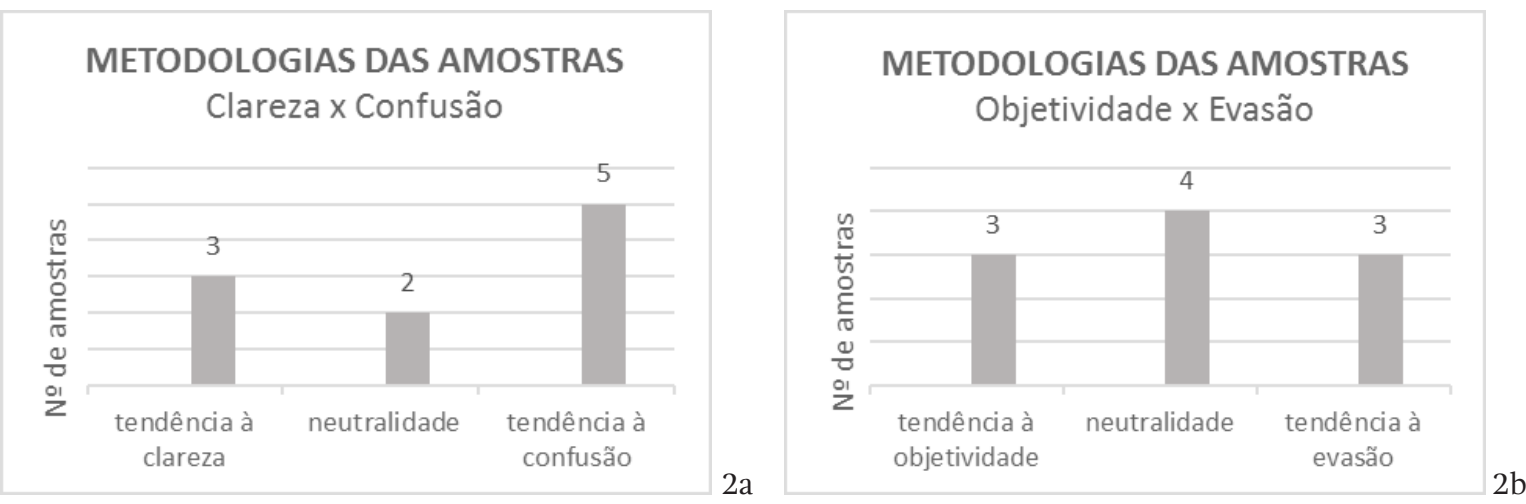

De acordo com os gráficos $2 \mathrm{a}$ e $2 \mathrm{~b}$, apenas três artigos apresentaram metodologias com discursos considerados claros e objetivos. A baixa compreensibilidade das ideias expostas nas metodologias das amostras pode indicar inconsistência de planejamento ou mesmo ser fruto das limitações de formato de publicação exigidas pelos periódicos e/ou evento científico.

Gráfico 2c Analise das metodologias das amostras quanto à coerência

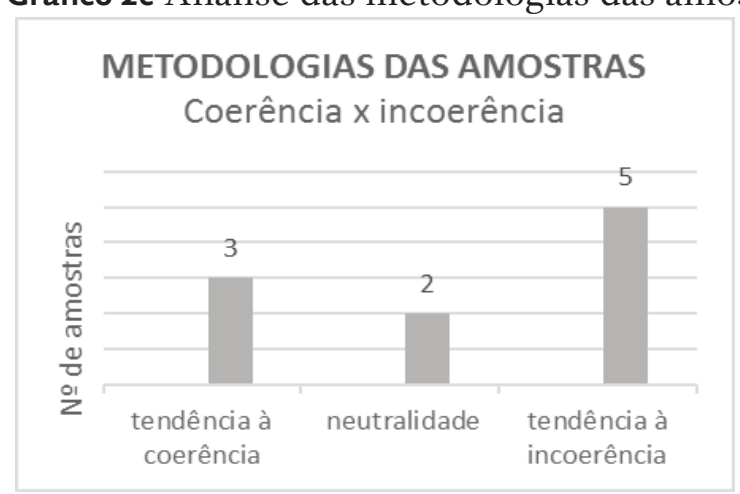

Os índices de incoerência encontrados nos discursos das metodologias (gráfico 2c) das amostras afetaram a compreensão do planejamento das pesquisas e a consistência na relação que deveria ser estabelecida com os objetivos. 
A incoerência metodológica pôde ser posteriormente associada às fragilidades encontradas no discurso das conclusões expostas pelos autores das amostras. Ao final dos textos da maioria das amostras (n7/ n10) foi possível reconhecer que as metodologias escolhidas por seus autores não produziram dados suficientes - ou mesmo condizentes - para responder aos objetivos de análise. Não havia, portanto, zonas comuns que pertencessem tanto os objetivos quanto à metodologia.

Gráfico 3a e 3b Analise das conclusões das amostras quanto à clareza e objetividade
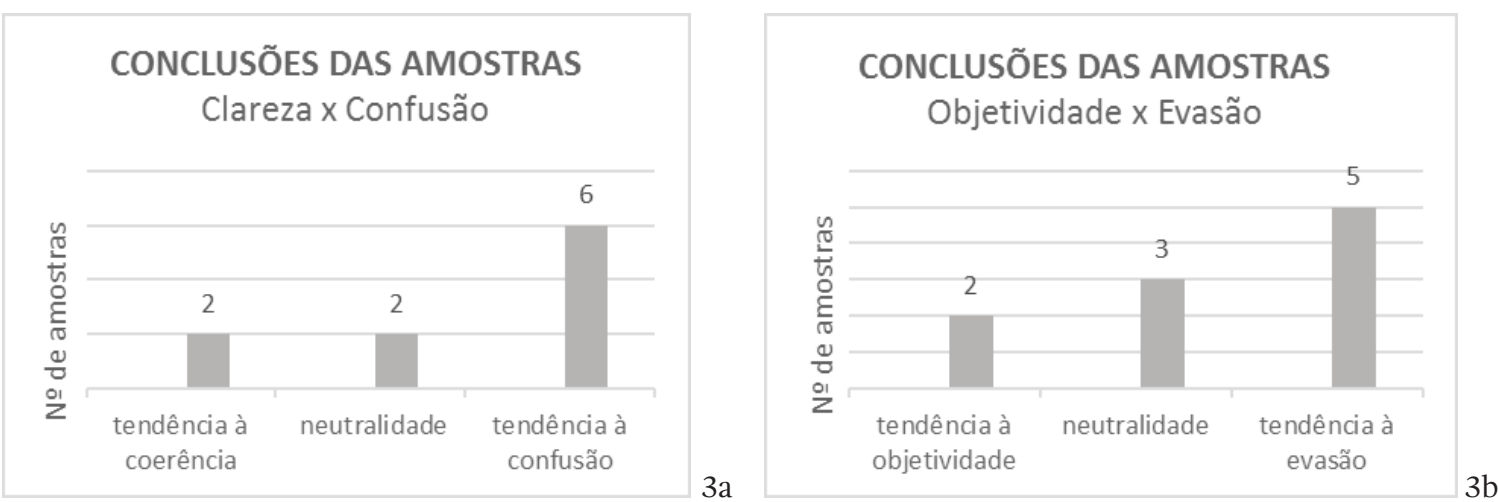

As falhas de associação entre o discurso dos objetivos e o discurso das metodologias proporcionaram que apenas duas amostras tenham alcançado as metas que foram estipuladas desde o início das pesquisas. Este fator é refletido na baixa incidência de clareza e objetividade das conclusões aferidas pelos autores das amostras.

Ao analisar o discurso presente nas conclusões dos dez artigos, poucos foram capazes de responder, de forma consistente e eficiente, as indagações que basearam os objetivos.

Como um castelo de cartas, as outras características (concisão, coerência e acuidade) investigadas também sofreram interferência negativa na classificação final da EDS na maioria das análises (n8/n10). O discurso geral das conclusões destas oito amostras exibiu fragilidade nas argumentações por meio de inferências superficiais ou mesmo de origem discordante com os dados obtidos.

\subsection{Resultados adicionais da análise com o EDS}

A pesquisa preliminar realizada através da Escala de Diferencial Semântico também foi capaz de expor dados gerais que, por vezes, extrapolaram a função inicial de sua aplicação, mas que, nem por isso, perderam sua importância:

- A maioria dos discursos dos artigos analisados não exibia justificativa para a realização das pesquisas. Isso pode interferir na solidez dos objetivos; 
- As inferências identificadas no discurso das conclusões da maioria dos artigos são de natureza generalista. Isto é fruto da obtenção de dados pouco relevantes ou da falta de acuidade para extrair o verdadeiro potencial que estes mesmos dados podem proporcionar;

- É comum os objetivos serem alcançados parcialmente. Esta característica pode ter origem no frágil planejamento dos objetivos, na incongruência escolha da metodologia utilizada ou na insuficiente exploração dos dados obtidos. Entretanto, esta insuficiente exposição das ideias pode, também, ser uma consequência do formato de publicação exigido pelos periódicos e/ou evento científico. Cada modalidade textual tem suas próprias regras que alteram a construção do discurso.

\subsection{Considerações sobre a Escala de Diferencial Semântico}

Após a utilização da Escala de Diferencial Semântico foi possível estabelecer considerações sobre vários aspectos desta ferramenta de análise:

- A EDS pode ser utilizada em análises de várias áreas do conhecimento, tendo em vista que a delimitação dos conceitos a serem investigados é diretamente ligada à necessidade e ao interesse do avaliador;

- A gradação de níveis de valoração ajuda a estabelecer tendências de intensidade de um conceito analisado. Assim, não há limites muito rígidos de julgamentos que possam "viciar" os resultados finais de uma análise;

- Os resultados da valoração de conceitos são passíveis de interpretações mais amplas e subjetivas de acordo com a capacidade de percepção do avaliador;

- Justamente por se tratar de uma análise de caráter subjetivo e que trabalha com valoração determinada pelo avaliador, sua replicabilidade pode apresentar discrepâncias nos resultados em função do próprio avaliador; mesmo sendo replicada pelo mesmo avaliador, há possibilidade que os resultados finais sejam diferentes, já que a internalização de significados de um conceito pode variar em função do tempo e mesmo das experiências de uma pessoa.

\section{Software Tropes v 8.4}

A empresa Semantic-Knowledge, responsável pela distribuição do software Tropes v 8.4, aponta que este programa computacional é destinado à análise/classificação semântica de conteúdo textual ou falado. Por meio de parâmetros de programação, esta ferramenta é capaz de classificar - de forma bastante precisa - os termos de uma 
construção textual, bem como estabelecer relações de associação de palavras.

Apesar das limitações inerentes aos sistemas computacionais, o Tropes v 8.4 disponibiliza, em sua interface, opções de cruzamento de parâmetros de busca e análise cujos resultados podem ser exibidos de diversas maneiras a critério do pesquisador.

Para iniciar as atividades com o Tropes v 8.4 é necessário um trabalho de tratamento do texto a ser analisado simplificando a linguagem através da eliminação de uma série de símbolos e artifícios linguísticos que confundem os parâmetros do software.

Superada esta etapa, o texto é inserido no banco de dados do programa e ele, automaticamente, processa uma varredura para classificação e contabilização dos termos existentes. Apesar de parecer sem importância, este procedimento de registro quantitativo dos termos é útil na identificação do foco do discurso do texto analisado.

Com alterações dos parâmetros de exibição é possível encontrar formas distintas de expor os dados quantitativos descobertos. Por exemplo, são disponibilizados gráficos em estilos variados que podem ajudar a interpretar os dados de formas complementares (Figura 2).

Figura 2 Gráfico gerado pelo software Tropes v 8.4 exibindo as palavras frequentemente associadas ao termo “cor” presente no artigo 'A importância da cor nos infográficos de divulgação científica' de Quattrer \& Gouveia (2010)

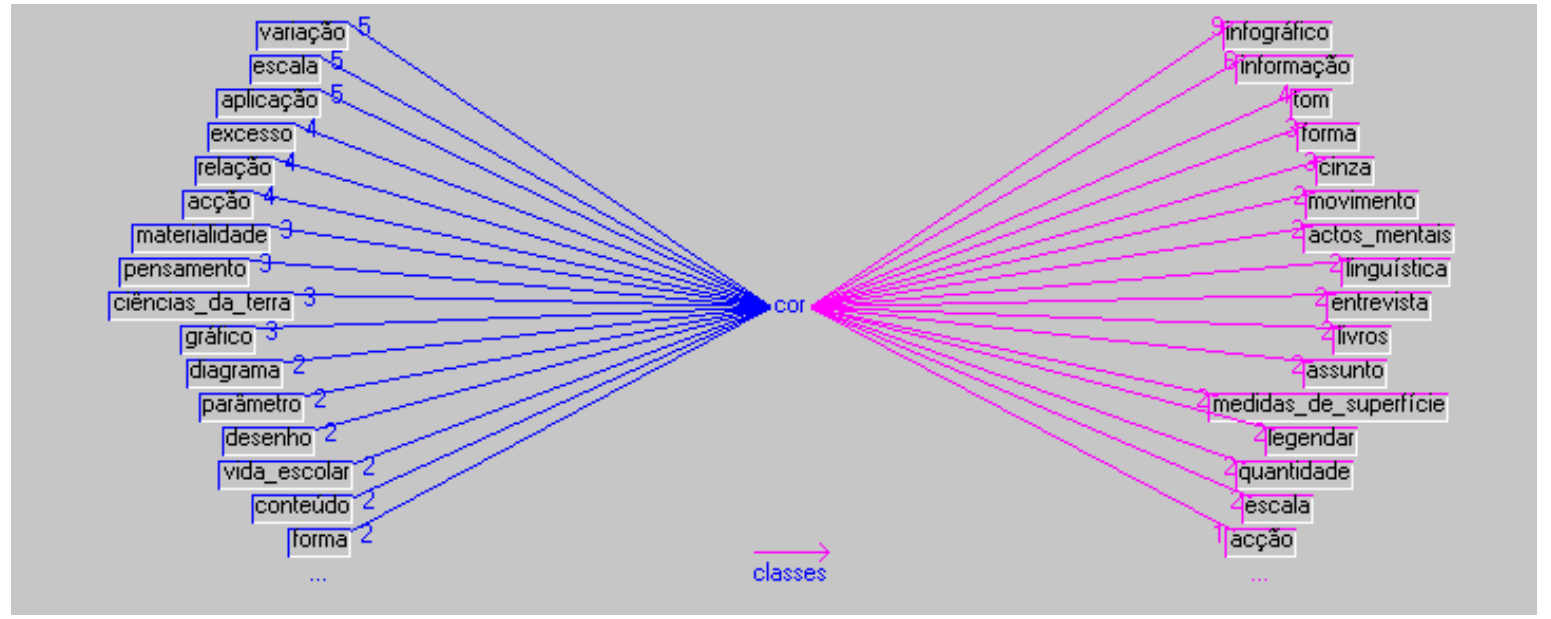

Apesar de pouco explicativas, as formas de apresentar os dados por meio de gráficos e infográficos parecem facilitar a compreensão das relações de associação entre termos e conceitos. Numa representação de gráfico de radiação, a aproximação dos termos-chave (representadas por esferas centrais) é representativa em um cenário de relações semânticas associativas primárias e secundárias - estas últimas apresentadas por esferas periféricas (Figura 3). 
Figura 3 Gráfico de radiação gerado pelo software Tropes v 8.4 exibindo a relação de associação dos termos "cor" e "infográfico" presentes no artigo “A importância da cor nos infográficos de divulgação científica’ de Quattrer \& Gouveia (2010). Os termos mais frequentes são representados por esferas maiores e suas conexões com os termos centrais são representados pela proximidade no plano bidimensional

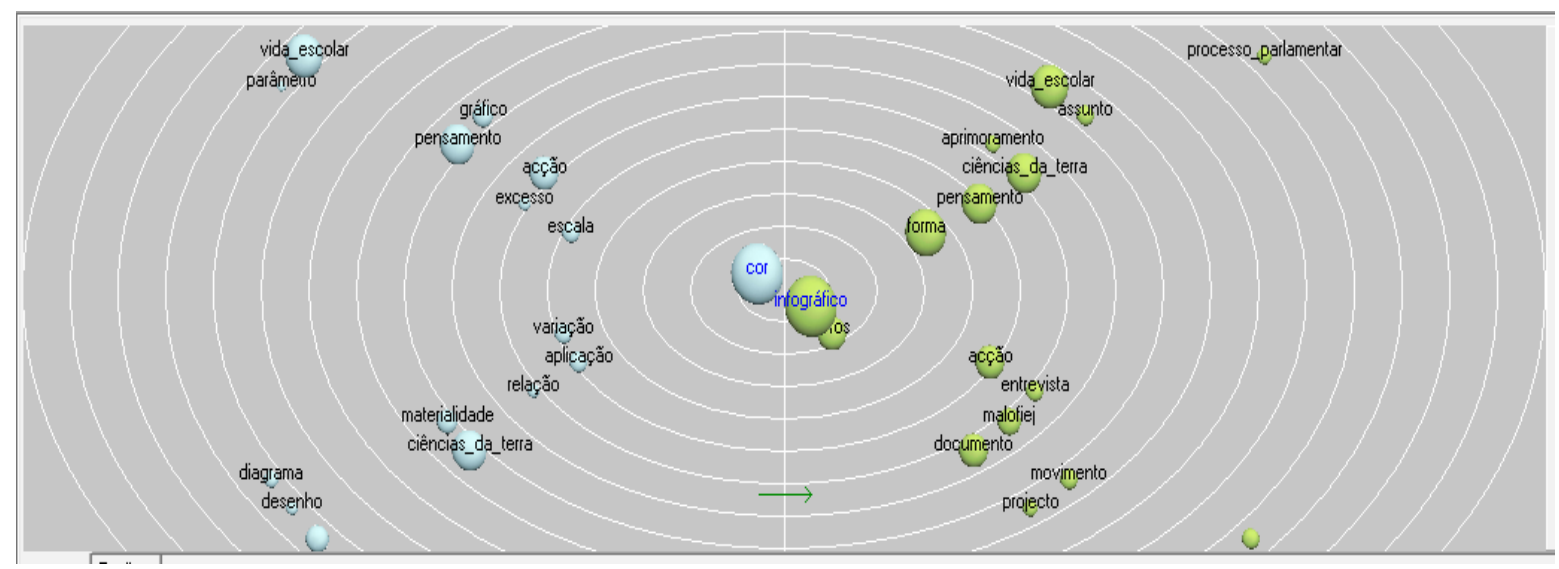

Diferentemente da análise semântica realizada através da Escala de Diferencial Semântico, a análise processada pelo Tropes v 8.4 não é capaz de interpretar o grau de clareza, objetividade, concisão, coerência ou acuidade do discurso científico, mas traz à tona diversos outros recursos de investigação semântica que enriquecem e dão solidez às pesquisas da área.

\subsection{Resultados da análise com o software Tropes v 8.4}

Após submeter os discursos dos componentes textuais (objetivos, metodologias e conclusões) de cada artigo científico investigado ao processamento de dados do software Tropes v 8.4, foi possível realizar as seguintes inferências:

- A maioria das pesquisas tem discurso concentrado nos termos estudados, ou seja, os termos indicados como objetos de análise são também os mais constantes durante o discurso da pesquisa;

- Nem sempre as associações entre termos secundários fazem parte do assunto central (foco) do discurso da pesquisa. Isto pode indicar que o discurso, apesar de ser mais focado nos termos centrais, não tem homogeneidade nos termos de apoio que deveriam dar coesão ao texto;

- A falta de coesão representada por termos secundários desvinculados do assunto central pode indicar um desvio do foco do discurso da pesquisa. Numa perspectiva cognitiva, a atenção do leitor pode estar sendo constantemente desviada da linha de discurso central da pesquisa; 
- $\quad$ O discurso das conclusões revelou menos foco nos termoschave da pesquisa do que o esperado. Em alguns casos, os termos centrais do discurso da pesquisa surgem como elementos secundários no discurso da conclusão.

\subsection{Considerações sobre o software Tropes v 8.4}

Após a utilização da Escala de Diferencial Semântico foi possível estabelecer considerações sobre vários aspectos desta ferramenta de análise:

- Os resultados apresentados pelo software são de natureza objetiva - se aproximando do universo estatístico - e, por isso, ideais para formulação de considerações sobre ênfase do discurso;

- A capacidade que o software tem de agrupar os termos em frequência de incidência ajuda a compreender quais conceitos são mais explorados e quais são os elementos centrais do discurso analisado;

- As características de associação de conceitos é uma importante ferramenta para pesquisas que envolvam Identificação da Representação Social;

- Apenas estes dados, predominantemente quantitativos, dificultam inferências profundas sobre a existência (ou ausência) de conexões entre os componentes textuais do discurso dos artigos analisados. Não é possível, portanto, estabelecer o grau de inter-relação entre os discursos dos objetivos, os discursos da metodologia e os discursos da conclusão de cada texto investigado;

- Apontado pela própria empresa que distribui o Tropes v 8.4, este software parece ser uma ferramenta útil para o estudo de associação de conceitos em questionários, grupo focal e entrevistas de pesquisas científicas. A capacidade de síntese do discurso observada durante a análise dos artigos científicos é indício de que este programa deve se enquadrar bem às necessidades provenientes destes tipos de coletas de dados.

\section{Comparação de instrumentos de análise semântica}

Apesar de não se configurar no foco desta pesquisa, a comparação entre os resultados obtidos pelas duas ferramentas de análise semântica foi compensadora.

A clara diferença na proposta de abordagem da Escala de Diferencial Semântico e do Software Tropes v 8.4 não impediu que o diálogo entre os dados obtidos, pelo contrário, proporcionou um processo de complementação. 
As principais características de cada instrumento podem ser observadas no quadro 1.

Quadro 1 Resumo das características individuais da Escala de Diferencial Semântico e do software Tropes v 8.4

\begin{tabular}{|c|c|c|}
\hline CARACTERÍSTICA & ESCALA DE DIFERENCIAL SEMÂNTICO & SOFTWARE TROPES V 8.4 \\
\hline Foco & $\begin{array}{l}\text { Foco na obtenção de dados com tendência } \\
\text { qualitativa através da interpretação subjetiva } \\
\text { de padrões. }\end{array}$ & $\begin{array}{l}\text { Foco na obtenção de dados de } \\
\text { tendência quantitativa através da } \\
\text { exposição estatística de conceitos e } \\
\text { associaçõos linguísticas. }\end{array}$ \\
\hline Parâmetros de análise & $\begin{array}{l}\text { Flexibilidade na alteração e/ou adição de } \\
\text { parâmetros de análise de acordo com as } \\
\text { necessidades do pesquisador. }\end{array}$ & $\begin{array}{l}\text { Flexibilidade na alteração e/ou adição } \\
\text { de parâmetros de análise de acordo } \\
\text { com as necessidades do pesquisador, } \\
\text { dentro de um universo limitado } \\
\text { de possibilidades. }\end{array}$ \\
\hline Inferências & $\begin{array}{l}\text { Por realizar uma análise de caráter mais } \\
\text { subjetivo, há grande possibilidade do } \\
\text { pesquisador extrapolar a dimensão dos } \\
\text { dados obtidos e realizar inferências } \\
\text { pouco justificadas. }\end{array}$ & $\begin{array}{l}\text { Por realizar uma análise de caráter } \\
\text { mais objetivo, o risco de extrapolação } \\
\text { da dimensão dos dados obtidos } \\
\text { é reduzido. }\end{array}$ \\
\hline Aplicação & $\begin{array}{l}\text { A capacidade de promover interpretação } \\
\text { de conceitos confere à esta ferramenta a } \\
\text { capacidade de se adaptar a qualquer área de } \\
\text { pesquisa e a qualquer técnica que busque } \\
\text { dimensionar/valorar conceitos. }\end{array}$ & $\begin{array}{l}\text { Apesar das limitações que a própria } \\
\text { tecnologia dispõe, o software faz } \\
\text { uma análise do caráter persuasivo } \\
\text { do discurso calcada em ênfases e } \\
\text { podem ser bem aproveitado em } \\
\text { análise cognitiva da mensagem } \\
\text { em questionários, grupo focal } \\
\text { e entrevistas. }\end{array}$ \\
\hline
\end{tabular}

Como demonstrado no quadro 2, as duas ferramentas de análise têm potencial para abranger um vasto universo de observação das relações textuais. Ao promover aspectos diferentes da abordagem semântica, ambas as ferramentas produzem dados que se complementam e auxiliam a construção de uma visão mais estruturada do objeto estudado.

Embora os objetos de estudos sejam distintos, Souza \& Fadel (2011) explicam a importância da utilização de ferramentas complementares para obtenção de dados mais completos numa pesquisa sobre narrativa em Design.

A "evidência empírica" pode ser analisada qualitativamente (por exemplo, o conteúdo, o discurso, a narrativa, etc.), quantitativamente (estatísticas descritivas ou inferenciais) ou uma combinação de ambas (pesquisa mista). (Souza \& Fadel, 2011:02) (Tradução livre).

Os autores (Ibid.) assinalam, por exemplo, que a evidência empírica extraída de experimentos controlados é, normalmente, analisada quantitativamente, enquanto evidência de perguntas abertas em entrevistas é analisada qualitativamente, ao mesmo tempo em que a análise quantitativa pode ser utilizada para complementar e, até mesmo, reforçar conclusões da análise qualitativa e vice-versa. 
Souza \& Fadel (2011:2) também argumentam que "a análise quantitativa é estatístico-descritiva quando utiliza quantidades e medida de dispersão" de forma a prover uma visão global de um conjunto de evidências empíricas, todavia, alertam os autores que "nenhuma conclusão pode ser feita a partir dessas informações". Noutra perspectiva, os autores indicam que a análise inferencial que utiliza testes estatísticos, que permitem conclusões particulares pode ser aplicada em contextos gerais. Portanto, a visão dos autores coaduna com os métodos adotados no presente estudo, embora de natureza distinta, e no nosso caso de forma preliminar.

Apesar das aparentes diferenças entre a EDS e o software Tropes v8.4, a formulação de conclusões acerca do conteúdo semântico é um processo que exige - no uso das duas ferramentas - elevado grau interpretativo do pesquisador.

O caráter qualitativo da Escala de Diferencial Semântico é assim denominado neste artigo por demandar, do pesquisador, a capacidade de planejamento, desde a construção da própria ferramenta na elaboração de questionamentos objetivos a serem respondidos e na eleição de parâmetros de análise (termos) claros em seu significado. Não é uma tarefa fácil, pois, o significado de um termo varia de pessoa para pessoa e, assim, de pesquisador para pesquisador.

No quesito interpretação dos resultados, o software Tropes v8.4 possui sua parcela de subjetividade. A exibição de dados 'crus', caracterizados por quantificações, não afasta a necessidade da interpretação do pesquisador. É preciso compreender o que as relações numéricas exibidas pelo software podem expressar sobre o contexto semântico.

Em resumo, em ambas as ferramentas o planejamento inicial do que se pretende responder pode ser mais importante que a utilização dos sistemas de análise. Nos dois casos, EDS e o software, os parâmetros de análise podem ser modificados à revelia do pesquisador e isso significa que as possibilidades de resultados são muito grandes, implicando em um risco considerável de se obter dados não pertinentes.

As aplicações de cada ferramenta seguem objetivos ligeiramente distintos. O software Tropes v8.4, segundo a empresa responsável por sua distribuição, foi desenvolvido com o intuito de promover análises do discurso persuasivo, ou seja, seu objetivo é investigar a incidência de termos e de mensagens dadas ao leitor. Para o presente estudo, esta característica ajuda a identificar o foco do discurso em trechos específicos, o que pode significar que um texto exiba uma mensagem de forma persistente ou evasiva.

A Escala de Diferencial Semântico, por sua vez, é uma ferramenta de aplicação em diferentes áreas e que pode ser adaptada aos objetivos de vários ramos de pesquisa. Para o presente estudo, a EDS trouxe a capacidade de valorar os parâmetros de análise mostrando nuances interpretativas. Esta característica ajudou a expor que algumas amostras poderiam ser classificadas como 'neutras' em determinados parâmetros, evitando injustiças provocadas por má classificação. 


\section{Considerações Finais}

Em sua jornada de autoconhecimento o designer enfrenta, paralelamente, barreiras para firmar-se como profissional de uma área do saber com credibilidade científica e é desafiado a estimular o aumento da produção de pesquisas científicas que deem visibilidade a seus estudos diante da comunidade acadêmica. Embora inserido dentro das ciências humanas e sociais aplicadas, as pesquisas desta área buscam adaptar-se ao hermetismo científico e produzir estudos que obedeçam às convenções comuns e exigidas pela academia.

As mesmas barreiras são identificadas quando se restringe a observação às produções científicas da área de Design da Informação. Os profissionais deste ramo, acostumados a manipular a mensagem e seus elementos informacionais, agora se deparam com o desafio de tentar manejar componentes da mensagem sobre a perspectiva da linguística.

Para investigar os esforços alcançados pelo Design da Informação no propósito de apresentar pesquisas científicas consistentes, este estudo analisou criticamente, de forma preliminar, o discurso de um pequeno grupo de dez artigos publicados em diferentes eventos científicos da área em questão.

Com o auxílio de duas ferramentas de análise (Escala de Diferencial Semântico e Software Tropes v 8.4) separadas por um período de 54 anos, os resultados obtidos podem indicar alguns equívocos ainda presentes na construção da maioria dos discursos investigados.

A característica com maior presença nos textos científicos da amostra analisada foi a aparente ausência de conectividade entre os objetivos propostos e a exposição da metodologia para atender a estes objetivos. A análise também mostrou que a fragilidade na relação desses dois componentes da pesquisa é associada à vulnerabilidade da estrutura argumentativa das conclusões.

Em outras palavras, as pesquisas em Design da Informação analisadas neste estudo apresentaram um discurso científico que nos parece incompleto ou fragmentado, o que leva a pensar que os componentes das pesquisas foram planejados separadamente e não como parte de um processo único. Este aparente ato de fragmentação do planejamento de pesquisa provoca um efeito dominó que desestabiliza a estrutura do discurso geral desde a escolha dos questionamentos a serem respondidos até a importância dos resultados obtidos.

Outra possível razão que pode interferir na conexão entre a metodologia e os objetivos, assim como proporcionar a fragmentação do discurso, é a própria rigidez exigida pelos periódicos e/ou eventos científicos na formatação dos artigos através da fixação de número especifico de palavras, de tópicos, etc. A concisão pode, portanto, ter sido um fator de considerável importância na exposição de ideias e na cadência do fluxo discursivo. 
Paralelo à formulação de considerações associadas ao objetivo deste estudo, foi realizado um processo comparativo entre duas técnicas de avaliação semântica cujos fundamentos têm origens em momentos diferentes da história da analise linguística e da evolução tecnológica.

Associar a análise subjetiva da Escala de Diferencial Semântico ao caráter quase estatístico do software Tropes v8.4 mostrou que, apesar de distintos, estes mecanismos de avaliação se complementam. Cada qual trata de um aspecto semântico que auxilia na construção de uma visualização mais abrangente do problema.

As considerações aqui apresentadas fazem parte de um estudo piloto, que representa uma fração do real cenário da produção cientifica do Design da Informação. É importante que outros instrumentos de investigação sejam aplicados e um número maior de textos seja submetido ao procedimento de análise semântica. Porém, é positivo observar que, apesar da pequena amostra, o processo de análise semântica do discurso foi capaz de proporcionar dados que auxiliem na acuidade discursiva e, mais profundamente, na construção de uma estrutura de pesquisa mais coesa sob uma perspectiva metodológica.

\section{Referências}

COSTA, J. C.; PEREIRA, V. W. (Orgs). 2009. Linguagem e cognição [recurso eletrônico]: relações interdisciplinares. Porto Alegre: EDIPUCRS, $331 \mathrm{p}$.

BARRASS, R. 1979. Os cientistas precisam escrever: guia de redação para cientistas, engenheiros e estudantes. São Paulo: T. A. Queiroz: EDUSP.

FOUCAULT, M. 1996. A ordem do discurso. São Paulo: Loyola.

KINTSCH, W. 1998. Comprehension: a paradigm for cognition. New York: Cambridge University Press.OSGOOD, C., SUCI, G., TANNENBAUM, P. 1957. The masurement of meaning. University of Illinois Press.

RUDIO, F. V. 1979. Introdução ao projeto de pesquisa cientifica. 2 ed. Petropolis: Vozes.

SALOMOM, D. V. 1999. Como fazer uma monografia: elementos de metodologia do trabalho cientifico. 9 ed. São Paulo: Martins Fontes.

SCHERER, L. C. 2009. Como os hemisférios cerebrais processam o discurso: evidências de estudos comportamentais e de neuroimagem. In: COSTA, J. C.; PEREIRA, V. W. (orgs) Linguagem e cognição [recurso eletrônico]: relações interdisciplinares, Porto Alegre: EDIPUCRS, cap 1, pp 77-102.

SOUZA, J M B; FADEL, L. M. 2011. To what extent is empirical research carried out by Brazilian information design researchers? In: Anais $5^{\circ} \mathrm{CIDI}$ Congresso Internacional de Design da Informação, $4^{0}$ INFODESIGN Congresso Brasileiro de Design da Informação, $5^{\circ}$ CONGIC Congresso Nacional de Iniciação Científica em Design da Informação. (CD-ROM). Florianópolis. SBDI/UFSC. 


\section{Anexo | Artigos analisados}

FARIA, P. C. L. A.; SOUTO, V. T. 2014. Linguagem gráfica de infográficos online do governo brasileiro: Um estudo de caso do Portal Brasil. Infodesign (SBDI. Online) v. 11, p. 320-336, 2014. Disponível em <http://www.infodesign.org. br/infodesign/article/view/264/202> Acesso em 08 de Jun de 2015

GOLFETTO, I. F.; GONÇALVES, B. S. 2010. Interatividade nas edições digitais de revistas In: Anais do $9^{\circ}$ Congresso Brasileiro de Pesquisa e Desenvolvimento em Design, São Paulo: Universidade Anhembi Morumbi, 2010. Disponível em <http://blogs.anhembi.br/congressodesign/anais/artigos/70156.pdf> Acesso em 08 de Jun de 2015

MOISSA, B.; BORBA, E. J.; KEMCZINSKI, A.; GASPARINI, I. 2014. Uma ferramenta de Visualização da Informação para analisar o comportamento do aluno em um ambiente e-learning e sua trajetória de aprendizagem. Infodesign (SBDI. Online), v. 11, p. 337-351, 2014. Disponível em <http://www.infodesign.org.br/ infodesign/article/view/318/203> Acesso em o8 de Jun de 2015

MOTTA, R. L.; CORREIA, W. F. 2013. Design de histórias em quadrinhos digitais: Criando novas mecânicas de leitura. In: Anais do XII Simpósio Brasileiro de Jogos e Entretenimento Digital, São Paulo: Outubro de 2013. Disponível em <http://www.sbgames.org/sbgames2013/proceedings/artedesign/18-dtpaper_Design\%2ode\%20HQ.pdf> Acesso em 08 de Jun de 2015

OLIVEIRA, P. R. M. 2010. Design de sites de encontro: estratégias de atração. In: Anais do 9º Congresso Brasileiro de Pesquisa e Desenvolvimento em Design, São Paulo. Mídia digital. São Paulo: Universidade Anhembi Morumbi. Disponível em <http://blogs.anhembi.br/congressodesign/anais/ artigos/69414.pdf> Acesso em 08 de Jun de 2015

QUATTRER, M.; GOUVEIA, A. P. S. 2010. A importância da cor nos infográficos de divulgação científica. In: Anais do $9{ }^{\circ}$ Congresso Brasileiro de Pesquisa e Desenvolvimento em Design, São Paulo: Universidade Anhembi Morumbi, 2010. Disponível em <http://blogs.anhembi.br/congressodesign/anais/ artigos/69285.pdf> Acesso em 08 de Jun de 2015.

QUATTRER, M.; GOUVEIA, A. P. S. 2013. Cor e Infográfico: O Design da Informação no livro didático. Infodesign (SBDI. Online) v. 10, p. 323-341, 2013. Disponível em <http://www.iar.unicamp.br/lis/dcf/cor-e-infografico_ MilenaQuattrer.pdf > Acesso em 08 de Jun de 2015

SANTOS COSTA, G. 2008. Multiletramento Visual na WEB. In: Anais do II Simpósio Hipertexto e Tecnologias na Educação - Universidade Federal de Recife- Pernambuco, setembro de 2008. Disponível em <https://www.ufpe. br/nehte/simposio2008/anais/Giselda-Costa.pdf > Acesso em o8 de Jun de 2015 .

SOUZA, J. M. B.; LIMA, R. C. 2013. Análise de representações gráficas de um evento dinâmico complexo: o gol de futebol. In: Proceedings of the 6th Information Design International Conference CIDI, 5th InfoDesign, 6th CONGIC (Blucher Design Proceedings, num.2, vol.1). São Paulo: Blucher, 2013. Disponível em < http://pdf.blucher.com.br/designproceedings/cidi//CIDI-11. pdf > Acesso em 10 de Nov. de 2015.

STUMPF, A.; GONÇALVES, B.S. 2012. O design do livro digital interativo: uma análise sobre a atuação dos profissionais envolvidos na produção do livro "A 
menina do narizinho arrebitado" para leitura em dispositivos tablet, In: Anais do XII Congresso de Ciências da Comunicação na Região Sul. Chapecó: 2012. Disponível em <http://www.intercom.org.br/papers/regionais/sul2012/ resumos/R30-0931-1.pdf> Acesso em 08 de Jun de 2015.

\section{Sobre os autores}

Elizabelle Pereira Costa

<elizabellecosta@gmail.com>

Meiriédna Queiroz Mota

<mqueirozmota@yahoo.com.br>

Solange Galvão Coutinho

<solangecoutinho@globo.com>

\section{Eva Rolim Miranda}

<evarolin@gmail.com>

Artigo recebido em 19 jul. 2015, aprovado em 03 dez. 2015. 